Relato de Caso

\title{
Falência ovariana precoce associada a deleção no braço longo do cromossomo: relato de dois casos e revisão da literatura
}

Premature ovarian failure with a deletion in the long arm of chromosome: report of two cases and review of the literature

Mariangela Badalotti ${ }^{1}$, Adriana Arent ${ }^{2}$, Aline Polanczick ${ }^{3}$, Rafaella Petracco ${ }^{4}$, Alvaro Petracco ${ }^{5}$

Resumo

Falência ovariana prematura pode ser idiopática ou estar associada a várias distúrbios auto-imunes ou genéticos, como as deleções do cromossomo X. Relatamos dois novos casos de deleções do braço longo do cromossomo X, em pacientes nuligrávidas apresentando amenorréia secundária e infertilidade. Nenhuma paciente referia história familiar de falência ovariana prematura e relatavam desenvolvimento puberal normal. A avaliação genética mostrou deleção distal no braço longo do cromossomo X, sendo os resultados 46,X,del(Xq22) e 46,X,del(Xq13q28), respectivamente. Após o diagnóstico as pacientes optaram por fertilização in vitro com óvulos doados.

PALAVRAS-CHAVE: Falência ovariana prematura; Deleção cromossômica; Amenorréia; Infertilidade

\section{Abstract}

Premature ovarian failure may be idiopathic or associated with several autoimmune and genetic disorders as X chromosome deletions. We report two cases of preamture ovarian failure associated with a deletion in the long arm of X chromosome. Both patients were nulligravidas presenting secondary amenorrhea and complaints of infertility, without family history of premature ovarian failure and reporting normal puberal development. Their karyotypes showed deletions of the distal long arm of all X chromosomes and were 46,X, del(Xq22) and 46,X, del(Xq13q28), respectively. After the diagnosis the patients decided to be submitted to an in vitro fertilization with egg donation.

KEYWORDS: Ovarian failure, premature; Chromosome deletion; Amenorrhea; Infertility

Serviço de Ginecologia do Hospital São Lucas da Pontificia Universidade Católica do Rio Grande do Sul - PUCRS - Porto Alegre (RS), Brasil; Fertilitat - Centro de Medicina Reprodutiva, Porto Alegre (RS), Brasil.

1 Professora da Faculdade de Medicina da Pontificia Universidade Católica do Rio Grande do Sul - PUCRS - Porto Alegre (RS), Brasil.

2 Preceptora do Serviço de Ginecologia do Hospital São Lucas da Pontificia Universidade Católica do Rio Grande do Sul - PUCRS - Porto Alegre (RS), Brasil.

3 Residente do Departamento de Ginecologia e Obstetrícia do Hospital São Lucas da Pontifícia Universidade Católica do Rio Grande do Sul - PUCRS

4 Acadêmica da Faculdade de Medicina da Universidade Luterana do Brasil - ULBRA - Canoas (RS), Brasil.

5 Professor da Faculdade de Medicina da Pontificia Universidade Católica do Rio Grande do Sul PUCRS - Porto Alegre (RS), Brasil.

Correspondência: Adriana Arent

Quintino Bocaiúva, 1617/301 - 90440-051 - Porto Alegre-RS - Fone/fax: (51) 3339-1142 - e-mail: adriarent@ig.com.br/fertilitat@fertilitat.com.br 


\section{Introdução}

Falência ovariana precoce (FOP) é definida como a finalização da função ovariana antes dos 40 anos; a incidência é de 1\% ao ano. É caracterizada por amenorréia secundária, hipoestrogenismo e gonadotrofinas elevadas em mulheres abaixo de 40 anos $^{1}$. A etiologia é complexa e inclui fatores genéticos (anomalias autossômicas e de cromossomos sexuais), imunes (como falência poliglandular, que afeta ovários, adrenal e tiróide), infecciosos (ooforites), metabólicos (galactosemia) e iatrogênicos (cirurgias, quimio e/ou radioterapia) ${ }^{2,3}$. As principais conseqüências da FOP são a perda da fertilidade e os efeitos clínicos do hipoestrogenismo, como a osteoporose $\mathrm{e}^{4,5}$.

Os cromossomos sexuais podem sofrer alterações tanto em seu número como na sua morfologia: cada um possui um braço curto (p) e um braço longo (q). Entre as alterações morfológicas mais importantes estão as deleções, produzidas pela perda de material genético. No caso do cromossomo X podem ocorrer deleções tanto no braço curto $(\mathrm{Xp})$ quanto no braço longo $(\mathrm{Xq})^{6,7}$. Outras alterações morfológicas são as translocações, que consistem no intercâmbio de material genético entre dois cromossomos homólogos, e a formação de isocromossomos.

A FOP é freqüentemente causada por aberrações do cromossomo $\mathrm{X}$. A literatura mostra que grandes anormalidades do cromossomo X, como a monossomia $\mathrm{X}$, resultam em amenorréia primária e alteração do desenvolvimento puberal (sindrome de Turner), ao passo que alterações leves, como as deleções parciais, são relacionadas à amenorréia secundária ${ }^{8}$. Nos últimos anos, com o acurado mapeamento das anomalias do cromossomo X, foram identificadas regiões específicas de Xq associadas a várias formas de $\mathrm{FOP}^{9}$. Achados de pesquisas sobre translocações balançadas x/autossômicas e deleções terminais Xq permitiram identificar dois loci independentes dentro do braço Xq, envolvidas na função ovariana. Estes loci estão localizados em Xq26-q28 (lócus FOP1 = falência ovariana prematura 1) e Xq13.3-q22 (FOP2 = falência ovariana prematura 2), respectivamente ${ }^{7,9}$. Ainda não está totalmente elucidado quais os genes envolvidos na FOP. No lócus FOP2, estudos de mapeamento de translocações revelaram três diferentes interrupções de genes em famílias com FOP, DIAPH2 (Diaphanous drosophilae homologue 2), DACH2 (Drosophilae daschund homologue 2) e FOP1B ${ }^{10,11}$. No lócus FOP1 nenhum gene foi identificado com certeza, apesar de associação entre premutações FMR1 e FOP terem sugerido que este gene atue como um fator de risco para FOP, com risco relativo estimado de aproximadamente $20 \%{ }^{12}$.
No presente estudo apresentamos dois casos de FOP em que a análise citogenética evidenciou deleções em Xq, nas regiões FOP2 isoladamente $(\operatorname{Del}(\mathrm{Xq} 22))$ e em associação com a região FOP1 (Del(Xq13q28)).

\section{Relato dos casos}

\section{Caso 1}

Paciente com 32 anos, encaminhada por FOP. A menarca ocorreu com 10 anos e o desenvolvimento puberal foi normal, tendo ciclos regulares até os 20 anos, quando começou a usar anticoncepcional combinado oral (ACO). Fazia intervalos a cada 3 meses e menstruava espontaneamente a cada pausa até o segundo ano de uso, quando fez pausa e não apresentou sangramento. Recebeu tratamento hormonal, menstruou e passou a usar ACO continuamente até dois anos atrás. Quando parou o $\mathrm{ACO}$, aos 30 anos de idade, ficou em amenorréia por quatro meses, foi medicada com progesterona e não menstruou. A seguir recebeu estrogênio + progesterona por via oral, tendo ocorrido sangramento após o uso. Nos três ciclos seguintes usou também citrato de clomifeno (CC) e menstruou nos dois primeiros. Após indução de sangramento com estrogênio e progesterona, usou CC por mais dois ciclos, nos quais não menstruou. Nestes ciclos fez dosagens de hCG, que sempre foram negativas. Quando veio à consulta estava sem uso de medicação e em amenorréia há 8 meses. Trazia exames recentes: prolactina $=15,7 \mathrm{mg} / \mathrm{L}, \mathrm{FSH}=62,3$ $\mathrm{mU} / \mathrm{mL}, \mathrm{LH}=21,9 \mathrm{mU} / \mathrm{mL}$ e ecografia transvaginal que mostrava útero e ovários diminuídos. $\mathrm{O}$ marido, hígido, não havia realizado exames.

Ao exame físico apresentava estatura normal, peso adequado, desenvolvimento de caracteres sexuais secundários e ausência de estigmas somáticos da sindrome de Turner. À avaliação ginecológica se observava vulva normal com atrofia vaginal. A ecografia pélvica visualizava corpo uterino e ovários de dimensões reduzidas, e endométrio linear. Negava história familiar de menopausa precoce, anormalidades genéticas e abortamentos.

Nesta consulta foram solicitados exames de linha imunológica (anticorpos anticardiolipina, anti-DNA, antitiroglobulina e antitiroperoxidase, e células LE, anticoagulante lúpico e A-TTP) e cariótipo. Foi também solicitado espermocitograma.

Os exames de ordem imunológica foram normais. O resultado do cariótipo (laboratório Amplicon, Porto Alegre), realizado em cultura de linfócitos de sangue periférico, foi 46,X,Del(Xq22) - 20 metáfases com bandeamento GTG e em todas foi observada deleção de parte do braço longo do cromossomo X (Figura 1). 


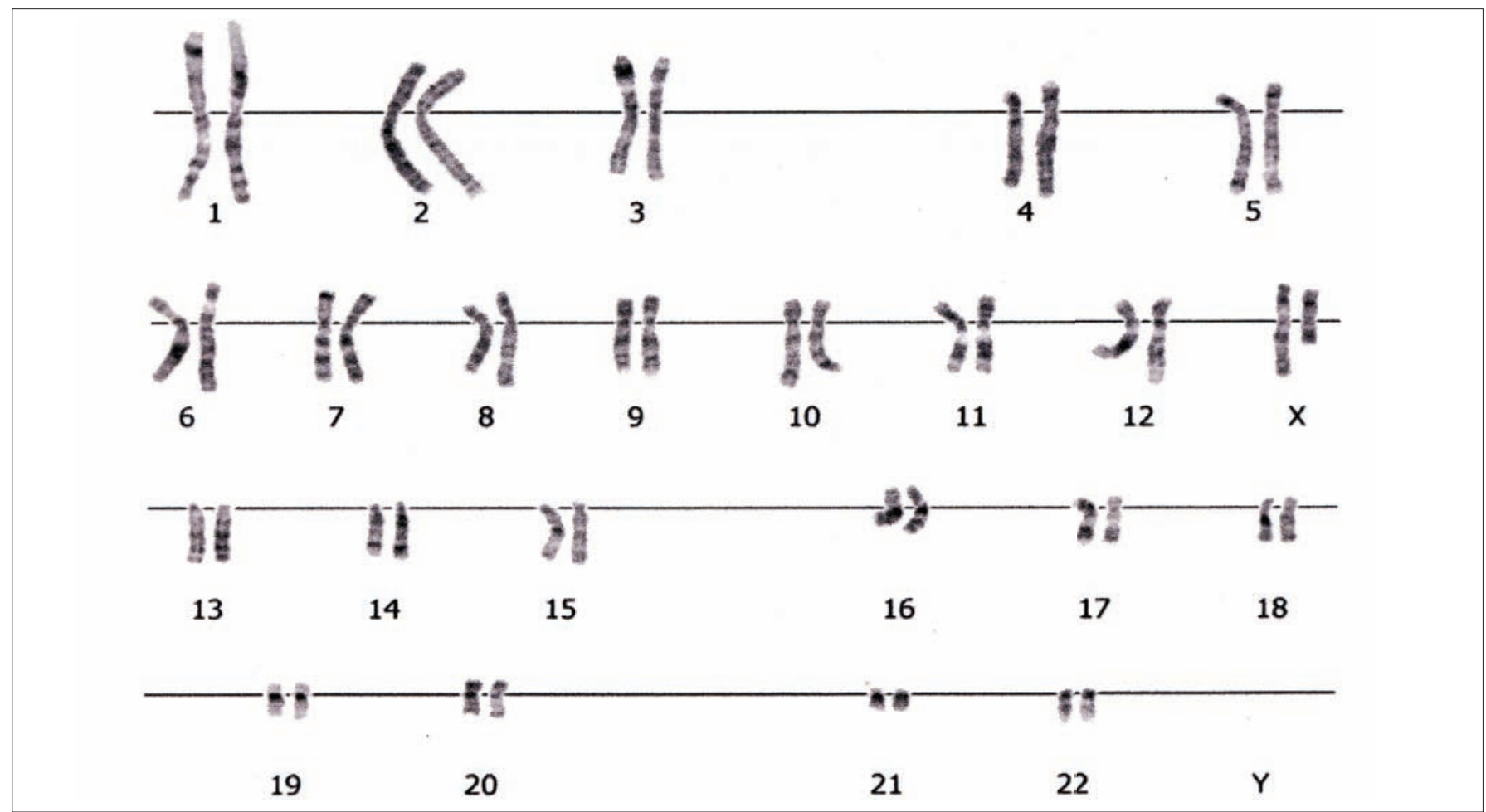

Figura 1 - Cariótipo com deleção no braço longo do cromossomo X (Del(Xq22)).

O espermograma mostrou oligospermia moderada (concentração $=8$ milhões $/ \mathrm{mL}$ ) e demais parâmetros normais.

Em face do diagnóstico foi discutida com a paciente a chance mínima de se obter sucesso na indução da ovulação, bem como o risco de transmissão de anormalidade do cromossomo X. O casal optou pelo tratamento do programa de fertilização assistida com doação de óvulos.

\section{Caso 2}

Paciente com 21 anos, encaminhada por amenorréia secundária e desejo de gestar. Relatava desenvolvimento puberal normal, com menarca aos 14 anos, apresentando o segundo episódio menstrual um ano após, seguido de amenorréia. Aos 16 anos procurou um ginecologista, foi prescrito Cicloprimogyna $^{\circledR}$, que utilizou por um ano. Durante este período apresentou sangramento vaginal regular nos intervalos entre as cartelas da medicação. Nega ter realizado exames laboratoriais naquela época. Após cessar o uso do estroprogestagênio, apresentou amenorréia secundária e episódios de sangramento uterino com freqüência anual até os 20 anos, quando foi encaminhada ao Serviço de Reprodução Humana do Hospital São Lucas (PUCRS). $\mathrm{Na}$ primeira consulta trouxe ecografia que evidenciava útero e ovário de tamanho reduzido.

Na história familiar referia ter quatro irmãos do sexo masculino, uma irmã com 24 anos que teve dois filhos de gestações sem intercorrências e mãe com seis gestações e seis partos, também sem intercorrências.

Ao exame físico apresentava peso, estatura e desenvolvimento de caracteres sexuais secundários normais, assim como vulva com trofismo adequado. Foram solicitados exames laboratoriais: FSH $58 \mathrm{mU} / \mathrm{mL}$; LH $16 \mathrm{mU} / \mathrm{mL}$; PRL 5,4 mg/L; E2 $32 \mathrm{mU} / \mathrm{mL}$. A ecografia confirmou o diagnóstico de útero reduzido de volume $\left(11 \mathrm{~cm}^{3}\right)$ e ovários com medidas inferiores a $1 \mathrm{~cm}$ no maior diâmetro. $\mathrm{O}$ resultado do cariótipo, realizado com cultivo celular de sangue periférico, observou 30 metáfases, todas com 46 cromossomos (laboratório Genex, Porto Alegre). A coloração através da banda $\mathrm{G}$ permitiu identificar uma deleção de grande parte do braço longo de um dos cromossomos sexuais 46,X,Del(X)(q13q28) (Figura 2). O marido apresentava espermograma normal. O casal foi encaminhado a programa de fertilização in vitro com doação de óvulos.

\section{Ética}

O anonimato das pacientes foi preservado neste relato, sendo apresentados apenas dados da história médica sem a identificação das mesmas. As pacientes consentiram em disponibilizar a utilização de seus dados para fins científicos, sendo este procedimento aprovado pelo Comitê de Ética em Pesquisa da Pontificia Universidade Católica do Rio Grande do Sul. 


\section{Discussão}

Apresentamos dois casos de falência ovariana prematura em que as pacientes apresentavam deleção parcial não mosaico do braço longo do cromossomo X, uma no lócus Xq22 (cariótipo 46,X,del(Xq22)) e outra no lócus Xq13q28 (cariótipo 46,X,del (Xq13q28)).

Anormalidades estruturais do cromossomo $\mathrm{X}$ produzem monossomia parcial dos braços curto ou longo ou de ambos. A monossomia X completa resulta na sindrome de Turner. Mulheres com linhagem celular $45, X$, com ou sem mosaicismo (46,XY, 46,XX, 47,XXX ou 46,XiXq), usualmente têm falência ovariana ${ }^{3,4}$.

As deleções parciais do cromossomo X têm sido relatadas, sendo a maioria de casos isolados com herança familiar $3,4,6,8,13$. Nos casos descritos a ausência de história familiar de menopausa precoce parece indicar que se tratem de deleções de novo do cromossomo X, embora não tenha sido realizada a investigação genética dos pais das pacientes.

Os efeitos da monossomia parcial dos braços do cromossomo X dependem da localização da região afetada. Em geral, deleções que afetam a região Xp11 resultam em falência ovariana na metade das mulheres, com algum grau de diminuição da função menstrual na outra metade. Nestas mulheres, mesmo com menstruação normal, a fertilidade é rara. Com deleções mais distais (Xp21) do braço curto, as alterações fenotipicas são geralmente leves, apesar de infertilidade e amenorréia secundária serem comuns. A maioria das pacientes com deleções Xp são de baixa estatura, independente da sua função ovariana, indicando a presença de outros genes determinantes da estatura nestas regiões ${ }^{14-16}$. As deleções do braço longo (Xq) usualmente causam falência ovariana quando envolvem a chamada região crítica (Xq13-q26). Apesar de a quase totalidade das pacientes com deleções nesta região terem falência ovariana, algumas exceções foram relatadas ${ }^{16}$. Similarmente às deleções do braço curto, as deleções proximais (Xq13) são usualmente mais graves. Ausência de telarca, amenorréia primária e falência ovariana ocorrem na maioria destas mulheres. Já nas deleções mais distais do braço longo a menarca pode ocorrer, com ou sem falência ovariana subseqüente ${ }^{6}$. Múltiplas alterações no cromossomo X estão relacionadas à fertilidade e à duração do período reprodutivo das mulheres ${ }^{6,8}$. A Tabela 1 apresenta características fenotípicas e a alteração genotipica de pacientes com deleções parciais do braço longo do cromossoma X.

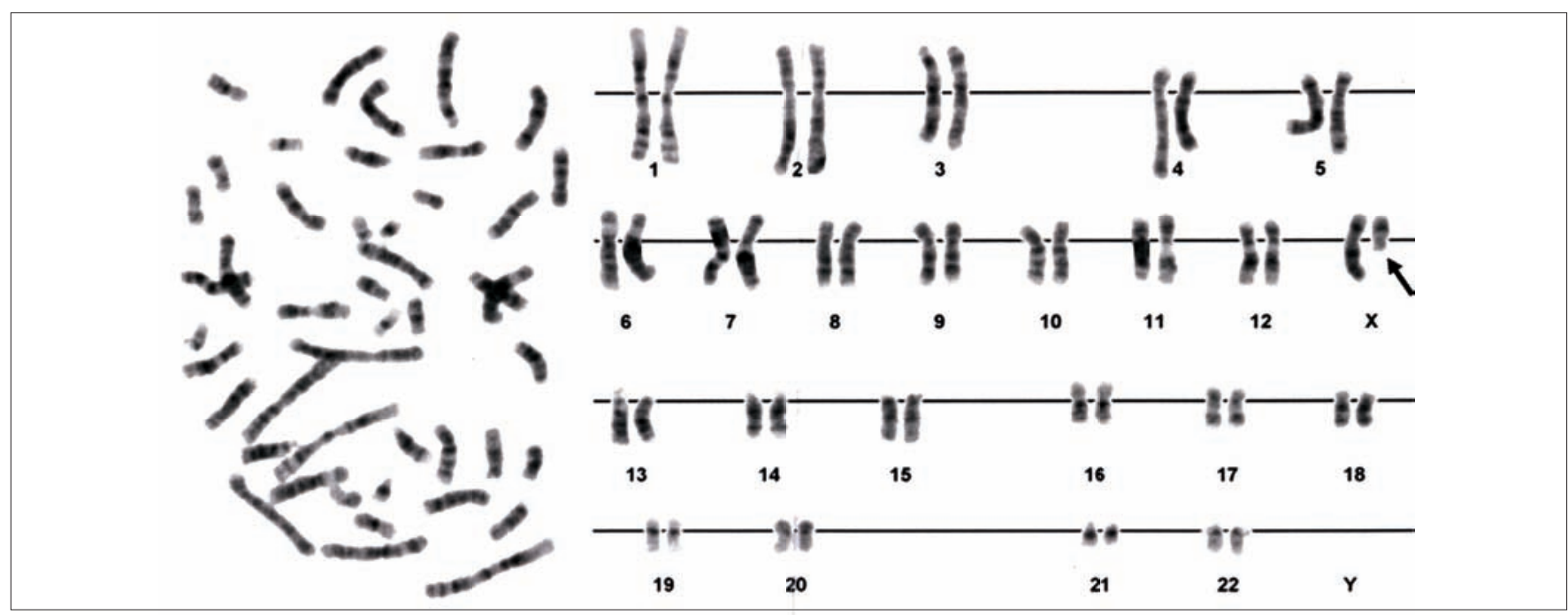

Figura 2 - Cariótipo com deleção no braço longo do cromossomo X: 46,X,Del(X)(q13q28).

Tabela 1 - Características de pacientes com deleções do braço longo do cromossomo X.

\begin{tabular}{|c|c|c|c|}
\hline Paciente & Genótipo & Fenótipo & Referência \\
\hline Paciente 1 & $46, X, \operatorname{Del}(X)(q 28)$ & Menopausa prematura 43 anos & Rossetti et al. ${ }^{13}$ \\
\hline Paciente 2 & 46,X,Del $(X)(q 28)$ & FOP, amenorréia secundária/17 anos & Rossetti et al. ${ }^{13}$ \\
\hline Paciente 3 & X46,X,Del (X)(q28) & FOP, amenorréia secundária/22 anos & Rossetti et al. ${ }^{13}$ \\
\hline Paciente 1 & 46,X,Del(X) (q26.2-q28) & FOP, amenorréia secundária/26 anos & Fimiani et al. ${ }^{7}$ \\
\hline Paciente 2 & 46,X,Del(X) (q26.2-q28) & Menopausa precoce/43 anos & Fimiani et al. ${ }^{7}$ \\
\hline Paciente 1 & 46,X,Del (Xq22) & FOP, amenorréia secundária/26 anos & Ishizuka et al. ${ }^{8}$ \\
\hline Paciente 1 & 46,X,Del $(X)(q 22)$ & FOP, amenorréia secundária & Presente estudo \\
\hline Paciente 2 & 46,X,Del (X) (q13-q26) & FOP, amenorréia secundária/15 anos & Presente estudo \\
\hline
\end{tabular}

FOP = falência ovariana precoce.

Rev Bras Ginecol Obstet. 2006; 28(9): 551-6. 
Nos casos por nós relatados, a paciente cuja deleção era localizada em Xq22 iniciou com episódio de amenorréia secundária aos 20 anos, porém aos 30 anos ainda apresentou reposta ovariana com sangramento após o uso de citrato de clomifeno, o que indicaria a existência de alguma função gonadal neste período. Já na paciente com deleção em Xq13q28 a FOP ocorreu aos 15 anos. Estes achados são condizentes com a literatura, que indica que quando as deleções do braço longo afetam a região crítica (Xq13-q26), usualmente causam falência ovariana ${ }^{17-19}$. Também concordam com os relatos de que as deleções proximais são usualmente mais graves, pois na paciente com deleção em Xq13, apesar do desenvolvimento puberal normal, a falência ovariana ocorreu com extrema precocidade. Foi sugerido que deleções distais que afetem o segmento cromossômico FOP1 resultam em falência ovariana entre 24 e 29 anos, ao passo que mutações em FOP2 causam disfunção ovariana mais precocemente, entre 16 e 21 anos $^{20}$.

No nosso relato não é possivel avaliar o impacto da deleção na região Xq28, uma vez que a paciente apresentava esta alteração associada a uma deleção de Xq13, considerada a região crítica. Talvez a gravidade da falência ovariana tenha sido influenciada por esta alteração associada.

Nos casos de deleções parciais do cromossomo o fenótipo talvez possa ser afetado por alterações ambientais. Isto foi sugerido em relato de deleção na região Xq28 no qual três mulheres de uma mesma família (mãe e duas filhas) apresentavam diferentes genótipos, apesar de serem afetadas por alteração genética idêntica. Neste relato a mãe teve menopausa prematura aos 43 anos, ao passo que as filhas entraram em amenorréia secundária aos 17 e 22 anos de idade $^{13}$. Outro estudo também achou comportamento semelhante em mãe com menopausa precoce e filha com FOP, ambas com deleções em Xq26.2-q28 . Estes relatos chamam atenção para

\section{Referências}

1. Luborsky JL, Meyer P, Sowers MF, Gold EB, Santoro N. Premature menopause in a multi-ethnic population study of the menopause transition. Hum Reprod. 2003;18(1):199-206.

2. Hoek A, Schoemaker J, Drexhage HA. Premature ovarian failure and ovarian autoimmunity. Endocr Rev. 1997;18(1):107-34.

3. Anasti JN. Premature ovarian failure: an update. Fertil Steril. 1998;70(1):1-15.

4. Shelling AN. X chromosome defects and premature ovarian failure. Aust N Z J Med. 2000;30(1):5-7. uma possivel diferença na penetração destes genes, que resultaria em diferentes graus de inativação do cromossomo X.

Manutenção da fertilidade tem sido descrita em pacientes com pequenas deleções Xq, antes do início da falência ovariana, sendo a alteração cromossômica transmitida para a prole ${ }^{21}$. Foram relatados três casos de deleção Xq25 em uma mãe e suas duas filhas, todas férteis, porém a mãe apresentou menopausa precoce ${ }^{21}$. Outro relato de caso apresentou sucesso na indução da ovulação de paciente com deleção Xq22 e amenorréia secundária hipergonadotrópica, porém sem obtenção de gravide ${ }^{8}$. Isto indicaria que as pacientes com este tipo de deleção sofrem aceleração à atresia folicular, porém os oócitos não são completamente depletados, principalmente se o tempo de amenorréia não for longo. Em nosso relato, a paciente com deleção Xq22 já estava há oito meses em amenorréia e havia oligospermia associada, sendo optado pela fertilização assistida com doação de óvulos. Porém, na história médica pregressa, chama atenção a ocorrência de sangramento seguido da indução com citrato de clomifeno, mesmo após quatro meses de amenorréia. Já a segunda paciente, com deleção Xq13q28, apresentava amenorréia secundária há 5 anos e diante da chance praticamente nula de sucesso de tentativa de indução da ovulação a opção foi também a fertilização in vitro com óvulos doados.

Concluímos que as anomalias cromossômicas devem ser descartadas nos casos de FOP surgidos antes dos 30 anos. Quando presentes, se existe desejo de gestação, deve ser oferecida a possibilidade de doação de óvulos, após inferência de fertilidade do parceiro por meio de espermocitograma.

\section{Conflito de interesses}

Os autores deste estudo não apresentam nenhum interesse financeiro ou de qualquer outra natureza relacionados à publicação deste artigo.

5. Rizzolio F, Bione S, Sala C, Goegan M, Gentile M, Gregato G, et al. Chromosomal rearrangements in $\mathrm{Xq}$ and premature ovarian failure: mapping of 25 new cases and review of the literature. Hum Reprod. 2006;21(6): 1477-83.

6. Layman LC. Genetic causes of human infertility. Endocrinol Metab Clin North Am. 2003;32(3):549-72.

7. Fimiani G, Laperuta C, Falco G, Ventruto V, D’Urso $M$, Ursini MV, et al. Heterozygosity mapping by quantitative fluorescent PCR reveals an interstitial deletion in Xq26.2-q28 associated with ovarian dysfunction. Hum Reprod. 2006;21(2):529-35. 
8. Ishizuka B, Kudo Y, Amemiya A, Ogata T. Ovulation induction in a woman with premature ovarian failure resulting from a partial deletion of the $\mathrm{X}$ chromosome long arm, 46,X,del(X)(q22). Fertil Steril. 1997;68(5):931-4.

9. Marozzi A, Manfredini E, Tibiletti MG, Furlan D, Villa $\mathrm{N}$, Vegetti W, et al. Molecular definition of Xq commondeleted region in patients affected by premature ovarian failure. Human Genet. 2000;107(4): 304-11.

10. Sala C, Arrigo G, Torri G, Martinazzi F, Riva P, Larizza L, et al. Eleven $\mathrm{X}$ chromosome breakpoints associated with premature ovarian failure (POF) map to a $15-\mathrm{Mb}$ YAC contig spanning Xq21. Genomics. 1997;40(1):123-31.

11.Bione S, Rozzolio F, Sala C, Ricotti R, Goegan M, Manzini MC, et al. Mutation analysis of two candidate genes for premature ovarian failure, $\mathrm{DACH} 2$ and POF1B. Hum Reprod. 2004;19(12):2759-66.

12.Sullivan AK, Marcus M, Epstein MP, Allen EG, Anido AE, Paquin JJ, et al. Association of FMR1 repeat size with ovarian dysfunction. Hum Reprod. 2005;20(2):402-12.

13. Rossetti F, Rizzolio F, Pramparo T, Sala C, Bione S, Bernardi $\mathrm{F}$, et al. A susceptibility gene for premature ovarian failure (POF) maps to proximal Xq28. Eur J Hum Genet. 2004;12(10):829-34

14.Layman LC, Reindollar RH. The genetics of hypogonadism. Infertil Reprod Med Clin North Am. 1994;5(1):53-68.
15.Layman LC. Familial ovarian failure. In: Lobo RL, editor. Perimenopause. New York: Springer Verlag; 1997; p. 54-63.

16. Simpson JL, Rajkovic A. Ovarian differentiation and gonadal failure. Am J Med Genet. 1999;89(4):186200.

17. Hassum Filho PA, Silva IDC, Vereschi ITN. O espectro das falências ovarianas ligadas ao cromossomo X. Arq Bras Endocrinol Metab. 2001;45(4):339-42.

18. Witchel SF, Wenger SL, Hoffman EP. Molecular and cytogenetic studies of $\mathrm{X}$ inactivation in a patient with 46,X,del(X)(q22). J Pediatr Adolesc Gynecol. $1997 ; 10(2): 78-82$.

19. Ogata T, Matsuo N. Turner syndrome and female sex chromosome aberrations: deduction of the principal factors involved in the development of clinical features. Hum Genet. 1995;95(6): 607-29.

20.McAuley K, Cambridge L, Galloway S, Sullivan $\mathrm{J}$, Manning P. De novo deletion of Xq associated with premature ovarian failure. Aust $\mathrm{N} \mathrm{Z} \mathrm{J} \mathrm{Med.}$ 2000;30(1):89-90.

21.Naguib KK, Sundareshan TS, Bahar AM, A1Awadi SA, Jeryan LA, Hamdan MR. Fertility with deletion Xq25: report of three cases; possible exceptions for critical region hypothesis. Fertil Steril. 1988;49(5):917-9. 